\title{
Transient iron overload with bleomycin detectable iron in the plasma of patients with adult respiratory distress syndrome
}

\author{
John M C Gutteridge, Gregory J Quinlan, Timothy W Evans
}

\begin{abstract}
Background - A retrospective study was conducted to evaluate iron status in plasma samples collected from five patients with the adult respiratory distress syndrome (ARDS) who had bleomycin detectable iron in at least one sample. Ten patients with ARDS with no evidence of bleomycin detectable iron and 10 healthy individuals served as controls.

Methods - Evidence of iron overload was established by measuring the percentage saturation of plasma transferrin. In each case the bleomycin assay for redox active, chelatable iron was used to measure plasma levels of non-transferrin bound iron in the low micromolar range; assays for total plasma iron and transferrin were performed to establish a diagnosis of transient iron overload. The effect of this on the ability of transferrin to act as a plasma antioxidant was assessed using two different assay systems.
\end{abstract}

Results - The five patients with evidence of transient iron overload (mortality 4/5) represented $33 \%$ of the total population of patients with ARDS (mortality 5/10) managed by the unit during the study period. All had low molecular mass iron detectable in their plasma and had clinical and biochemical evidence of multiorgan system failure as well as liver impairment. Compared with the ARDS and normal control populations, transferrin and albumin levels were low and the former failed to act as a plasma antioxidant in preventing free radical mediated damage to detector molecules.

Conclusions - Patients with ARDS are thought to be under severe oxidative stress from their disease and from treatment with high inspired oxygen concentrations. A subgroup of patients with ARDS has been identified who displayed evidence of transient iron overload as a result of which their plasma iron binding antioxidant protection was greatly compromised. This finding must be considered a serious additional risk factor for oxidative stress.

(Thorax 1994;49:707-710)

The adult respiratory distress syndrome (ARDS) is associated with many precipitating factors. ${ }^{1}$ Although the lungs are usually the first organ to undergo life threatening damage, multisystem failure often ensues. The mechanisms leading to acute lung injury are uncertain, but recent evidence suggests that patients with ARDS experience oxidative stress from several sources. Thus, in plasma and bronchoalveolar lavage fluid there is evidence of oxidative damage to proteins ${ }^{2}$ and lipids, ${ }^{3}$ increased excretion of hydrogen peroxide in the breath ${ }^{4}$ and decreased levels of low molecular mass plasma antioxidants have been identified. ${ }^{35}$ Oxidative stress in the lungs may be due to the accumulation of neutrophils which, upon activation, secrete superoxide $\left(\mathrm{O}_{2}{ }^{-}\right)$, hydrogen peroxide $\left(\mathrm{H}_{2} \mathrm{O}_{2}\right)$, and hypochlorous acid $(\mathrm{HOCl})$, and the unavoidable use of high inspired oxygen concentrations $\left(\mathrm{FIO}_{2}\right)$.

Superoxide and hydrogen peroxide are not themselves damaging oxidants, but in the presence of redox active iron complexes they have been shown to serve as precursors of the aggressive and highly reactive hydroxyl radical $(\cdot \mathrm{OH}){ }^{6}$ Iron capable of catalysing the formation of $\mathrm{OH}$ radicals is not present in the plasma of normal healthy individuals, ${ }^{7}$ since it remains tightly sequestered to the iron transport protein transferrin. Transferrin is normally one third loaded with iron and retains a considerable iron binding capacity which confers on it a potent antioxidant activity towards iron driven radical reactions. ${ }^{8}$ However, iron saturation of transferrin leads to the presence of bleomycin detectable iron in plasma, thereby conferring pro-oxidant activity towards free radical damage to selected detector molecules. In the present retrospective study we identified a subpopulation of patients with ARDS who showed periods of transient iron overload during their stay in intensive care.

\section{Methods}

PATIENT POPULATION

Diagnosis of ARDS

ARDS was diagnosed clinically in patients with refractory hypoxaemia (ratio of arterial oxygen tension $\left(\mathrm{PaO}_{2}\right)$ to fractional inspired oxygen concentration $\left(\mathrm{FIO}_{2}\right)<20$ SI units), evidence of diffuse bilateral pulmonary infiltrates on chest radiography, and a pulmonary artery occlusion pressure $<18 \mathrm{~mm} \mathrm{Hg} .{ }^{9}$ The extent of lung injury was also quantified using the lung injury score (LIS) of Murray et al described in detail elsewhere. ${ }^{10}$ All patients with ARDS had a pulmonary artery catheter in situ and were managed using modes of mechanical ventilation, an $\mathrm{FIO}_{2}$ and inotropic agents sufficient to produce an oxygen delivery index of $300 \mathrm{ml} / \mathrm{min} / \mathrm{m}^{2}$. Routine haematological and 
biochemical tests, including those of liver function, were performed daily.

\section{Study protocol}

In our unit patients with ARDS have blood taken for analysis as frequently as possible (maximum daily) for the period during which they meet the diagnostic criteria outlined. In every case $10 \mathrm{ml}$ arterial blood is withdrawn at 07.45 hours into a lithium heparin tube, centrifuged immediately at $2000 \mathrm{~g}$, and the plasma separated and stored at $-20^{\circ} \mathrm{C}$. A sample is not taken if the patient is absent for an investigation, if the blood cannot be centrifuged immediately, or if the clinical diagnosis of ARDS cannot be sustained.

In a retrospective analysis of the blood samples taken over a 12 month period those patients who had evidence of transient iron overload, based on the presence of bleomycin detectable iron in their plasma, were compared with those who did not in terms of biochemical findings, LIS, and clinical outcome, and with the biochemical results of 10 normal controls.

\section{ASSAYS}

Total non-haem iron and the iron binding capacity were measured spectrophotometrically using a kit (Sigma Chemical Co, Poole, Dorset, UK) based on the ferrozine assay. The bleomycin detectable iron assay which measures chelatable redox active iron was also used. ${ }^{71}$ Briefly, bleomycin is allowed to bind to linear duplex DNA and chelate any low molecular mass iron present in the plasma. Addition of ascorbate redox cycles the iron bound to DNA causing oxidative damage to the deoxyribose moiety releasing malondialdehyde, which is measured spectrophotometrically by reaction with thiobarbituric acid. Total plasma proteins were determined using a kit (Sigma Chemical Co, Poole, Dorset, UK) based on the Lowry technique. Transferrin was quantitated using radial immunodiffusion plates containing a polyclonal antibody to human transferrin. Two different plasma antioxidant assays were applied to assess changes involving the iron loading of transferrin. In the first assay system the ability of plasma to inhibit the degradation of DNA by bleomyciniron-ascorbate, generating a reactive oxo-iron species, was determined. ${ }^{12}$ Secondly, the ability of plasma to inhibit iron stimulated per-

Table 1 Clinical and demographic details of patients studied

\begin{tabular}{|c|c|c|c|c|}
\hline $\begin{array}{l}\text { Patient } \\
\text { no }\end{array}$ & $\begin{array}{l}\text { Age } \\
\text { (years) }\end{array}$ & $\begin{array}{l}\text { Underlying } \\
\text { diagnosis }\end{array}$ & LIS at entry & Outcome \\
\hline $\begin{array}{l}\text { A } \\
\text { B } \\
\text { C } \\
\text { D }\end{array}$ & $\begin{array}{l}67 \\
21 \\
63 \\
57\end{array}$ & $\begin{array}{l}\text { Pneumonia } \\
\text { Pneumonectomy } \\
\text { Post CAVG } \\
\text { Sepsis after } \\
\text { abdominal surgery }\end{array}$ & $\begin{array}{l}7 \\
4 \\
7 \\
3\end{array}$ & $\begin{array}{l}\text { Died } \\
\text { Died } \\
\text { Died } \\
\text { Survived }\end{array}$ \\
\hline $\begin{array}{l}\text { E } \\
\text { ARDS } \\
\text { controls } \\
(n=10)\end{array}$ & $\begin{array}{l}76 \\
24(15-59)\end{array}$ & $\begin{array}{l}\text { Decortication } \\
\text { Wide variety }\end{array}$ & $\begin{array}{l}6 \\
3 \cdot 3(0 \cdot 2)\end{array}$ & $\begin{array}{l}\text { Died } \\
5 \text { survivors }\end{array}$ \\
\hline $\begin{array}{l}\text { Normal } \\
\text { controls } \\
(n=10)\end{array}$ & $32(18-39)$ & $\mathrm{N} / \mathrm{A}$ & $\mathbf{N} / \mathbf{A}$ & N/A \\
\hline
\end{tabular}

LIS = lung injury score; $N / A=$ not applicable oxidation of phospholipid liposomes, involving lipid radicals, was measured..$^{13}$ All assays were performed in duplicate. The precision of the assays has been described in detail elsewhere. ${ }^{1213}$ All results shown are mean (SE). Comparisons between groups were made using the Mann-Whitney $U$ test and $p$ values $<0.05$ were considered significant.

\section{Results}

Five patients (mean age 56, range $21-76$ years) representing a third of the total patient population studied in the specified time period fulfilled the diagnostic criteria for ARDS and were shown to have bleomycin detectable iron in their plasma. All had evidence of severe lung injury (LIS at entry 5.4 (0.8)) resulting from a range of underlying diseases. Four of the five patients eventually died, each having evidence of at least three organ system failures as defined by Knaus $e t a l^{14}$ at the time of their first blood sample (table 1). By comparison, the 10 ARDS control patients were younger (mean age 24, range 15-59), had less severe lung injury (LIS at entry $3.3(0.2), \mathrm{p}<0.05)$ and a lower mortality (five survivors).

Thirteen blood samples were available from the five patients, of which six showed the presence of bleomycin detectable iron (1.20 $(0.60) \mu \mathrm{mol} / 1$ for the six samples, table 2$)$. In most cases the plasma transferrin was at or near complete iron saturation when bleomycin detectable iron was detectable in the plasma, and the resulting iron overload was often transient in nature (table 2). For all the plasma samples analysed in this subgroup total nonhaem iron values were slightly, but not significantly, higher (18.6 (4.30)) than healthy control subjects $(15.7(6.05))$ or patients with ARDS without iron overload (14.9 (2.13)) (table 2). The percentage saturation of the plasma transferrin for the subgroup was significantly higher $(71.0 \quad(6.9) \%)$ than that measured in both control groups $(25 \cdot 6(8 \cdot 8) \%$ and $33.9(3.8) \%)$. Plasma transferrin levels were extremely low $(0.82(0.13) \mathrm{g} / \mathrm{l})$ for the iron overloaded patients with ARDS compared with the ARDS $(1.76(0.13) \mathrm{g} / \mathrm{l})$ and normal $(3.06(0.41) \mathrm{g} / \mathrm{l})$ control groups. Total proteins were lower in the subgroup $(50.7$ $(1 \cdot 16) \mathrm{g} / \mathrm{l})$ than in the ARDS control group $(69 \cdot 5(5 \cdot 17) \mathrm{g} / 1)$. Together with the transferrin levels, these results probably reflect decreased liver synthesis of protein. During the period of transient iron overload all five patients had a degree of impaired liver function based on plasma bilirubin levels (table 3). The iron loading of plasma transferrin, together with the extremely low levels of transferrin present, gave this subgroup of patients with ARDS severely compromised antioxidant protection against iron mediated free radical damage in vitro. As a group they showed a mean prooxidant status, stimulating damage to DNA in vitro compared with the inhibition seen in ARDS control patients, and only $27 \%$ antioxidant protection against iron stimulated phospholipid peroxidation compared with $66 \%$ in the ARDS control group (table 2). 
Table 2 Plasma iron and antioxidant values in patients with ARDS showing transient iron overload

\begin{tabular}{|c|c|c|c|c|c|c|}
\hline \multirow{2}{*}{$\begin{array}{l}\text { Patient code } \\
(\text { day } / \text { month })\end{array}$} & \multirow{2}{*}{$\begin{array}{l}\text { Total iron } \\
(\mu \mathrm{mol} / \mathrm{l})\end{array}$} & \multirow{2}{*}{$\begin{array}{l}\text { Transferrin } \\
(\mathrm{g} / \mathrm{l})\end{array}$} & \multirow{2}{*}{$\begin{array}{l}\% \text { saturation of } \\
\text { transferrin }\end{array}$} & \multirow{2}{*}{$\begin{array}{l}\text { Bleomycin detectable } \\
\text { iron }(\mu \mathrm{mol} / \mathrm{l})\end{array}$} & \multicolumn{2}{|c|}{ Iron binding antioxidant activities } \\
\hline & & & & & DNA degradation & Lipid peroxidation \\
\hline A $25 / 4$ & $29 \cdot 2$ & 1.54 & 73 & $0 \cdot 76$ & $32 \%(\mathrm{~S})$ & $3 \%(S)$ \\
\hline $\begin{array}{l}\text { B } 11 / 6 \\
12 / 6\end{array}$ & $\begin{array}{l}13 \cdot 1 \\
14 \cdot 8\end{array}$ & $\begin{array}{l}0.59 \\
0.78\end{array}$ & $\begin{array}{l}85 \\
72\end{array}$ & $\begin{array}{l}0 \\
0 \cdot 43\end{array}$ & $\begin{array}{l}53 \%(\mathrm{I}) \\
18 \%(\mathrm{~S})\end{array}$ & $\begin{array}{c}64 \%(\mathrm{I}) \\
9 \%(\mathrm{~S})\end{array}$ \\
\hline $\begin{array}{r}\text { C } 26 / 7 \\
29 / 7 \\
31 / 7\end{array}$ & $\begin{array}{l}46 \cdot 4 \\
38 \cdot 2 \\
-\end{array}$ & $\begin{array}{l}0.99 \\
1.65 \\
-\end{array}$ & $\begin{array}{c}100 \\
89 \\
-\end{array}$ & $\begin{array}{l}1 \cdot 20 \\
0 \cdot 68 \\
0\end{array}$ & $\begin{array}{r}46 \%(\mathbf{S}) \\
26 \%(\mathbf{S}) \\
3 \%(\mathbf{S})\end{array}$ & $\begin{array}{l}2 \%(\mathrm{~S}) \\
12 \%(\mathrm{I}) \\
42 \%(\mathrm{I})\end{array}$ \\
\hline $\begin{array}{c}\text { D } 23 / 11 \\
24 / 11 \\
25 / 11 \\
1 / 12\end{array}$ & $\begin{array}{r}7 \cdot 7 \\
6 \cdot 4 \\
4 \cdot 5 \\
-\quad\end{array}$ & $\begin{array}{l}0.40 \\
0.40 \\
0.59 \\
-\end{array}$ & $\begin{array}{l}73 \\
61 \\
29 \\
-\end{array}$ & $\begin{array}{l}0 \\
0 \\
0 \\
0 \cdot 03\end{array}$ & $\begin{array}{c}39 \%(I) \\
34 \%(I) \\
43 \%(I) \\
5 \%(S)\end{array}$ & $\begin{array}{l}1 \%(I) \\
24 \%(I) \\
36 \%(I) \\
-\end{array}$ \\
\hline $\begin{array}{r}\mathrm{E} 1 / 12 \\
2 / 12 \\
5 / 12\end{array}$ & $\begin{array}{r}27 \cdot 0 \\
9 \cdot 3 \\
8 \cdot 0\end{array}$ & $\begin{array}{l}0.69 \\
0.59 \\
0 \cdot 78\end{array}$ & $\begin{array}{r}100 \\
60 \\
39\end{array}$ & $\begin{array}{l}4 \cdot 08 \\
0 \\
0\end{array}$ & $\begin{array}{c}173 \%(\mathrm{~S}) \\
56 \%(\mathrm{I}) \\
38 \%(\mathrm{I})\end{array}$ & $\begin{array}{l}19 \%(\mathrm{~S}) \\
92 \%(\mathrm{I}) \\
84 \%(\mathrm{I})\end{array}$ \\
\hline Mean (SE) & $18 \cdot 6(4 \cdot 30)$ & $0.82(0 \cdot 13)$ & $71 \cdot 0(6 \cdot 9)$ & $1.20(0.6)^{*}$ & $3 \cdot 1(17 \cdot 2)(S)$ & $26 \cdot 9(10 \cdot 7)(\mathrm{I})$ \\
\hline $\begin{array}{l}\text { Normal adult } \\
\text { controls } \\
(n=10)\end{array}$ & $15 \cdot 7(6 \cdot 05)$ & $3.06(0.41)$ & $25 \cdot 6(8 \cdot 8)$ & 0 & $61 \cdot 3(1.5)(I)$ & $86.4(3.6)(I)$ \\
\hline $\begin{array}{l}\text { Control ARDs } \\
\text { patients } \\
(\mathbf{n}=10)\end{array}$ & S $14.9(2 \cdot 13)$ & $1.76(0 \cdot 13)$ & $33.9(3.8)$ & 0 & $46.5(2.94)(I)$ & $65 \cdot 6(3 \cdot 7)(\mathrm{I})$ \\
\hline
\end{tabular}

$\mathrm{I}=$ inhibition; $\mathrm{S}=$ stimulation; $-=$ no sample available for assay.

*Value only for samples with bleomycin detectable iron.

Table 3 Liver function tests in patients with ARDS showing transient iron overload

\begin{tabular}{|c|c|c|c|c|c|c|}
\hline $\begin{array}{l}\text { Patient code } \\
\text { (day/month) }\end{array}$ & $\begin{array}{l}\text { Bilirubin } \\
(\mu \mathrm{mol} / \mathrm{l})\end{array}$ & $\begin{array}{l}(A K P) \\
(u / l)\end{array}$ & $\begin{array}{l}\alpha G T \\
(u / l)\end{array}$ & $\begin{array}{l}A S T \\
(u / l)\end{array}$ & $\begin{array}{l}\text { Total protein } \\
(\mathrm{g} / \mathrm{l})\end{array}$ & $\begin{array}{l}\text { Albumin } \\
(\mathrm{g} / \mathrm{l})\end{array}$ \\
\hline $\begin{array}{lc}\text { A } & 25 / 4 \\
\text { B } & 11 / 6 \\
& 12 / 6 \\
\text { C } 26 / 7 \\
29 / 7 \\
\\
\text { D } 23 / 7 \\
\text { D } 24 / 11 \\
& 24 / 1 \\
& 25 / 11 \\
\text { E } & 1 / 12 \\
& 2 / 12 \\
& 3 / 12\end{array}$ & $\begin{array}{r}107 \\
12 \\
34 \\
155 \\
371 \\
484 \\
52 \\
58 \\
37 \\
66 \\
54 \\
27\end{array}$ & $\begin{array}{r}751 \\
99 \\
119 \\
185 \\
305 \\
271 \\
100 \\
103 \\
139 \\
172 \\
200 \\
125\end{array}$ & $\begin{array}{r}242 \\
14 \\
18 \\
48 \\
48 \\
38 \\
28 \\
31 \\
45 \\
98 \\
120 \\
56\end{array}$ & $\begin{array}{r}51 \\
35 \\
55 \\
2852 \\
212 \\
146 \\
16 \\
14 \\
27 \\
24 \\
24 \\
23\end{array}$ & $\begin{array}{l}51 \\
46 \\
51 \\
50 \\
51 \\
49 \\
44 \\
48 \\
51 \\
56 \\
59 \\
52\end{array}$ & $\begin{array}{l}20 \\
28 \\
31 \\
37 \\
32 \\
31 \\
26 \\
27 \\
26 \\
26 \\
25 \\
26\end{array}$ \\
\hline $\begin{array}{l}\text { Normal } \\
\text { range in adult } \\
\text { controls }\end{array}$ & $2-15$ & $80-250$ & $11-51$ & $15-41$ & $62-82$ & $34-48$ \\
\hline
\end{tabular}

$\mathrm{AKP}=$ Alkaline phosphatase; $\alpha \mathrm{GT}=$ gamma glutamyl transferase; $\mathrm{AST}=$ aspartate transferase.

\section{Discussion}

Patients with ARDS appear to be under severe oxidative stress from both the disease process and treatment with high inspired oxygen concentrations. Evidence of oxidative molecular damage to lipids and proteins and antioxidants can therefore be detected in plasma and bronchoalveolar lavage fluids taken from such patients. ${ }^{15}$ In a previous study we noted that patients with ARDS but no evidence of multiorgan system failure or iron overload have changes in iron metabolism leading to decreased antioxidant protection when compared with normal healthy controls. Both increased iron loading of plasma transferrin and decreased ability to catalyse the oxidation of ferrous ions to the ferric state (ferroxidase activity) have been described in these patients. ${ }^{12}$ Transferrin and caeruloplasmin (ferroxidase I) are two primary plasma antioxidants that function in concert to protect the body against iron toxicity that can lead to oxygen radical formation. ${ }^{13}$ The catalysed oxidation of ferrous ions by caeruloplasmin allows the resulting ferric ions to bind to transferrin, making sure there is no reactive unbound iron present in normal plasma. The bleomycin assay detects and measures loosely bound, redox active iron and, since its introduction, ${ }^{71}$ the assay has made it possible to monitor levels of chelatable iron in extracellular fluids. Bleomycin is not able to remove iron from the two high affinity iron binding sites of transferrin or lactoferrin ${ }^{711}$ or from correctly iron loaded ferritin. Previous studies have shown that, when transferrin is highly loaded but not fully saturated with iron, bleomycin detectable iron can still appear in the plasma. ${ }^{16}$ This suggests that some of the chelatable iron present in plasma during certain pathological conditions is not correctly loaded onto the high affinity binding sites of transferrin.

Bleomycin detectable iron has previously been found in the plasma of patients with idiopathic haemochromatosis, ${ }^{17}$ leukaemic patients on chemotherapy, ${ }^{18}$ and in umbilical cord and neonatal plasma. ${ }^{1920}$ As far as we are aware this is the first report of a similar finding in patients with ARDS. Only one of the patients in this subgroup had conditions associated with iron overload - namely cirrhosis whilst all had evidence of liver impairment. Although the study population represented only $33 \%$ of the patients with this condition 
managed in our ICU during a 12 month study period, they had a particularly high mortality $(80 \%)$ compared with the group as a whole $(60 \%)$. Furthermore, the subgroup consisted of older patients with more severe injury as indicated by LIS. Lastly, four of the five patients in the subgroup had evidence of three or more organ system failures at entry compared with only five of 10 controls. Although the current investigation is too small to draw conclusions as to whether iron overload has a causal relation with multiorgan system failure and death or represents a consequence of severe illness, non-transferrin bound low molecular mass iron is a pro-oxidant form of iron that must pose a potential hazard to biological systems. The observation that such iron can appear even transiently in the plasma of some patients with ARDS who are already under considerable oxidant stress is of considerable interest for future studies directed towards antioxidant intervention in patients with severe lung injury.

JMCG holds the first BLF/BOC Senior Fellowship in respiratory critical care and thanks: the British Lung Foundation an the British Oxygen Group for their generous support. GJQ an TWE thank the BLF, BOC and the Wolfson Trust for financia support. The authors thank the Department of Clinical Pathology for performing the liver function tests, and Sharon Mumby for undertaking the antioxidant assays.

1 Montgomery B, Stager MA, Carries CJ, Hudson LD. Causes of mortality in patients with the adult respiratory distress syndrome. Ann Intern Med 1985;132:485-9.

2 Quinlan GJ, Evans TW, Gutteridge JMC. Plasma protein damage in ARDS. Thorax 1993;48:430P

3 Richard C, Lemonnier F, Thibault $M$, Couturier $M$ Anzepy P. Vitamin E deficiency and lipo-peroxidation during adult respiratory distress syndrome. Crit Care Med 1990;18:4-9.

4 Baldwin SR, Grum CM, Boxer LA, Simon RH, Ketai LH, Devah LJ. Oxidant activity in expired breath of patients wevah LJult 1986;i:11-14.
5 Cross CE, Forte T, Stocker R, Louie S, Yamamoto Y, Ames BN, et al. Oxidative stress and abnormal cholesterol metabolism in patients with adult respiratory distres syndrome. F Lab Clin Med 1990;115:391-404.

6 Gutteridge JMC, Halliwell B. Iron toxicity and oxygen radicals. In: Hershko C, ed. Clinical haematology: iron chelating therapy. London: Balliere Tindall, 1989, 195256.

7 Gutteridge JMC, Rowley DA, Halliwell B. Superoxide dependant formation of hydroxyl radicals in the presence of iron salts. Detection of "free" iron in biological systems by using bleomycin-dependent degradation of DNA. Biochem f 1988;199:263-5.

8 Gutteridge JMC, Paterson SK, Segal AK, Halliwell B. Inhibition of lipid peroxidation by the iron binding protein lactoferrin. Biochem $\mathcal{f} 1981 ; 199: 259-61$.

9 Macnaughton PD, Evans TW. The adult respiratory distress syndrome. Lancet 1992;339:469-72.

10 Murray JF, Matthay MA, Luce JM, Flick MR. An expanded definition of the adult respiratory distress syndrome. Am Rev Respir Dis 1988;138:720-3.

11 Gutteridge JMC, Hou Y. Iron complexes and their reactivity in the bleomycin assay for radical-promoting looselybound iron. Free Radic Res Commun 1986;2:143-51.

12 Gutteridge JMC, Quinlan GJ, Evans TW. Primary plasma antioxidants are decreased in patients with adult respiratory distress syndrome. I Lab Clin Med 1994;(in press)

13 Gutteridge JMC, Quinlan GJ. Antioxidant protection against organic and inorganic oxygen radicals by normal human plasma: the important primary role for iron bindhuman plasma: the important primary role for iron binding and iron oxidis

14 Knaus WA, Draper EA, Wagner DP, Zimmerman JE. Prognosis in acute organ system failure. Am $\mathcal{f}$ Surg 1985;202:685-93.

15 Halliwell B, Gutteridge JMC, Cross CE. Free radicals antioxidants and human disease: where are we now? $\mathcal{f} \mathrm{Lab}$ Clin Med 1992;119:598-620.

16 Gutteridge JMC. Bleomycin-iron in biological fluids. What does this assay measure? In: Rice-Evans $C$, Halliwell $B$ eds. Free radical methodology and concepts. London: Richelieu Press, 1988:429-46.

17 Gutteridge JMC, Rowley DA, Griffiths E, Halliwell B Low molecular weight iron complexes and oxygen radical reactions in idiopathic haemochromatosis. Clin Sci 1985;68:463-7.

18 Halliwell B, Aruoma OI, Mufti G, Bomford A. Bleomycindetectable iron in serum leukaemic patients before and after chemotherapy. FEBS Lett 1988;241:202-4

19 Lindeman JHN, Hondkamp E, Lentjes EGW, Poorthuis $\mathrm{BJH}$, Berger HM. Limited protection against ironinduced lipid peroxidation by cord blood plasma. Fre Radic Res Commun 1992;16:285-94.

20 Evans PJ, Evans R, Kovar IZ, Holton AF, Halliwell B. Bleomycin-detectable iron in the plasma of premature and full-term neonates. FEBS Lett 1992;303:210-2. 